\title{
EL TIPO ICONOGRÁFICO DE LAS BRUJAS Y HECHICERAS DE LA ANTIGUA GRECIA
}

\section{THE ICONOGRAPHIC TYPE OF THE WITCHES AND SORCERESSES OF ANCIENT GREECE}

\author{
María Vázquez Alba \\ (Universidad de Málaga, España) \\ mariavazquezalba21@gmail.com
}

Recibido: 02 abril 2020 Aceptado: 20 mayo 2020 Publicado: 01 julio 2020

Resumen: La magia ha existido en todos los periodos de la antigüedad. En la Grecia clásica estaba muy presente en todos los ámbitos de la vida, aunque no era bien recibida. Esta condena se acentúa cuando las personas que realizaban estas prácticas mágicas eran mujeres, conocidas como brujas y hechiceras que, al mismo tiempo, eran protegidas y respaldadas por diosas relacionadas con esta disciplina. Todas ellas se ganaron un lugar dentro de aquellas mujeres vejadas por la sociedad debido a estos conocimientos místicos que reunían. A pesar de esto, sus historias han pervivido hasta nuestros días, así como su representación artística a lo largo de la Historia de Arte.

Palabras clave: magia, bruja, Antigüedad, iconográfico.

\begin{abstract}
Magic has existed in all periods of antiquity. In classical Greece it was very present in all areas of life, although it was not well received. This condemnation is accentuated when the people who performed these magical practices were women, known as witches and sorceresses who, at the same time, were protected and supported by goddesses related to this discipline. All of them gained a place among those women vexed by society due to these mystical knowledges that they gathered. Despite this, their stories have survived to this day, as well as their artistic representation throughout the History of Art.
\end{abstract}

Keywords: magic, witch, Antiquity, iconographyc. 


\section{La figura de las brujas y hechiceras en la Antigua Grecia}

Es conocido que durante la Grecia clásica la magia obtuvo una gran presencia como disciplina, pudiendo ser esto debido al contacto con otras civilizaciones bárbaras, aumentando así el gusto por la veneración de ciertos aspectos místicos o de gran poder misterioso. Podemos localizar en el periodo helenístico el momento en el que la mujer comienza a tener un papel importante a nivel práctico dentro de este mundo de magia y espiritualidad. La mujer siempre se ha considerado distinta al hombre, poseyendo el poder de dar la vida como característica profundamente sagrada y mística desde el mundo Antiguo, y en muchas ocasiones vinculada esta con la naturaleza, la Tierra y la Luna. A diferencia de los dioses, las brujas y hechiceras adquirían sus "poderes" mediante una línea de aprendizaje, que las llevaba de ser unas iniciadas sin conocimiento a convertirse en aquellos personajes que actuaban por sí mismos sin evocaciones a potencias superiores, pero con un enorme potencial y saber. (García, 2005, p. 36)

\section{Las grandes brujas y hechiceras}

\section{Circe, la primera gran bruja}

La figura de Circe nos viene dada por una de las fuentes clásicas más conocidas actualmente, La Odisea de Homero (Homero, 1974). En esta obra se cuenta como Odiseo (Ulises) se embarca en un viaje junto con sus hombres teniendo que enfrentarse a numerosos problemas y aventuras. Circe aparece en el relato cuando Odiseo le cuenta sus lances a Alcínoo, rey de los feacios, narrándole el momento en el que llegan a la isla de Eea donde habitaba la joven. Ella invita a los marineros de Odiseo a entrar y los convierte con su bastón o varita (que sabemos es su principal utensilio de hechicería) y un brebaje, en cerdos. Odiseo, avisado por uno de sus hombres que no entró en la morada de Circe, ingresa en el lugar con la intención de acabar con la bruja llevando consigo una planta llamada molly (Luck, 1995, p. 42) para que esta no pudiera transformarlo al igual que a sus compañeros. La joven de gran astucia le pide que mantenga relaciones sexuales con ella ya que solo así les devolverá el aspecto original a los marineros. Todo esto transcurre según lo previsto para ambos personajes, gozando todos después de la hospitalidad de la 
diosa durante un buen tiempo (un año), recibiendo a su partida los consejos de la mujer. (Wulff Alonso, 1997, pp. 15-19)

Aquí vemos la visión que se tiene de Circe en la literatura y en el arte, este ser poderoso que superó a su madre en conocimientos y en la ciencia de los encantamientos cuando llega a su edad adulta, que convierte a los hombres en otros especímenes, y que a su vez utiliza su evidente belleza para seducir al protagonista de la historia. Esto tiene cierta tendencia artística y literaria de presentarla como lo que hoy día conocemos como femme fatale (Dijkstra, 1986, pp. 273, 321), muy impulsado por los prerrafaelitas, como una mujer astuta y con numerosos conocimientos, pero que usa de forma confiada su cuerpo para atraer a sus víctimas, aunque en este caso, sin una lujuria evidente. Ella es el arquetipo de bruja enamorada, conquistada por la fuerte sexualidad de Odiseo, que parece haberse desplazado hacia un ámbito donde puede combinar sus diferentes condiciones como la de ser sobrenatural, una bruja con amplios conocimientos de plantas y conjuros de diferente tipo. Se la asocia con diferentes penas amorosas, siendo dominada por una fiera pasión que conduce sus actos, envuelta en un enorme misterio por Homero al situarla en un lugar lejano (aunque esto también puede ser un elemento común entre las brujas).

Circe, a causa de sus actos, se ve como una de esas brujas maléficas o de carácter oscuro, cuya proximidad inspira brutales pasiones (Levi, 1988, p. 60), aunque sabemos que ese componente malvado en cierto momento se torna en algo bueno ya que cuando los marineros recuperan su forma original lo hacen más jóvenes y con mejor aspecto que antes, y cuando Odiseo deja su hogar ella le aconseja qué debe hacer respecto a los peligros que se va a encontrar en el camino.

Cuando vemos las representaciones de Circe, es común verla acompañada por cerdos, esos animales en los que transformó a los marineros que viajaron con Odiseo, y que solían ser su principal compañía. No obstante, también puede aparecer con otros animales por la capacidad que poseía de domesticarlos. Los principales atributos que podemos relacionar o asociar con la diosa son la varita y la copa o el cuenco. La varita era la principal "arma”, de Circe, con la que realizaba sus conjuros y transformaciones, y el cuenco que usaba para contener sus venenos y pócimas como la que les dio a los compañeros de Odiseo antes de transformarlos en cerdos (Wulff Alonso, pp. 16-22). También puede estar acompañada de una buena cantidad de libros, recetarios, etc. 
Además no es raro ver en sus representaciones un espejo con el reflejo de Odiseo, como hace Waterhouse [1], ayudando a mostrar la carnalidad de la bruja, apoyada por el vestido vaporoso y translucido, además de estar rodeada de flores purpuras que vienen a significar la visión que tenía de sí misma como reina de su propia isla (Dijkstra, p. 321).

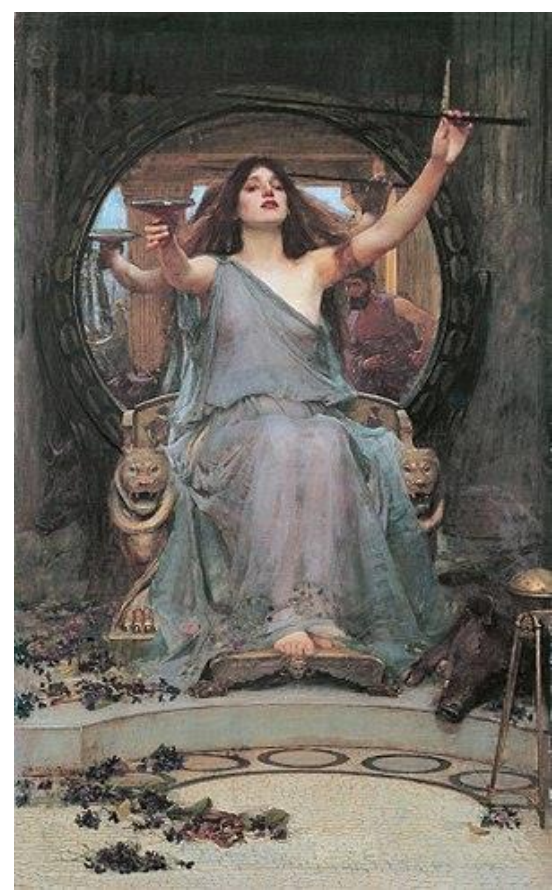

1. Waterhouse, J. (1891), Circe ofreciendo la copa a Ulises. Oldham Art Gallery: Oldham, Inglaterra

\section{Medea, la bruja trágica}

En la historia de Medea se han visto variaciones de su genealogía, pero finalmente se ha dilucidado que era hija del rey Eetes, como se indica en las Tragedias (Eurípides, 1977, p. 204) de Eurípides, por lo que se convertiría en sobrina de Circe. El personaje de Medea se conoce a través de su participación en la Argonautica (Rodas, 1996, p. 20). En uno de los viajes de los Argonautas, el grupo llega al país de Ea donde reina Eetes, el hermano de Circe, buscando el Vellocino de Oro, un objeto maravilloso que surge de la piel de un carnero con el pelaje de color dorado y que poseía propiedades mágicas. El rey accede a entregárselo, pero antes Jasón debe superar una serie de pruebas que finalmente cumple, pero gracias, precisamente, a la magia de Medea, la hija del rey, que queda prendada del joven héroe durante las referidas pruebas. Por este hecho, el personaje de Jasón se ha visto como un hombre con una personalidad oscurecida debido a que en raras ocasiones realiza nada por sí mismo, como vemos en la participación de Medea en este episodio 
(Elvira Barba, 2008, pp. 423-424). Pese a que el rey realmente no quería entregarle el vellocino, finalmente Medea le ayuda a conseguirlo drogando al dragón que lo custodiaba, y huye con ella a Grecia. Medea, al ver que su padre los perseguía, mata a Apsirto, su propio hermano, despedazándolo y lanzando su resto al mar para así retrasar la persecución a manos de su padre. Zeus, al ver esto, decide castigarlos con una fuerte tempestad, necesitando entonces la ayuda de Circe para que los purificara (Apolodoro, 1985, p. 79).

Pelias, el tío de Jasón, no contaba con el regreso de este y de su ahora esposa Medea a Yolco, por lo que determina asesinar a su hermano Esón, el padre del héroe, que viéndose en esa situación decide asesinarse él mismo bebiendo la sangre de un toro hasta morir. Jasón, ansiando venganza, pide ayuda de nuevo a Medea, que engaña a las hijas del tío de su marido para que estas despedazasen y posteriormente cocinaran a su padre, ya que la bruja les aseguró que después lo rejuvenecería con sus drogas. Después de esto, la pareja es expulsada de Yolco por el hijo de Pelias, Acasto. Llegan a Corinto donde pasan diez años rodeados de paz y felicidad, hasta que su rey, Creonte, le ofrece a Jasón la mano de su hija Glauce, que este acepta, abandonando entonces a Medea y sus hijos. La bruja, enfurecida, le envía un peplo envenenado a la futura novia de su esposo, abrasándola con un voraz fuego al igual que al padre de esta, que intentó salvarla. Existen variantes sobre lo que pasó después con los hijos de Medea. Se piensa que, o bien los mató despechada huyendo posteriormente en un carro de dragones que el dios Helios le entregó, o que fueron asesinados por los corintios cuando Medea los abandonó en el altar de Hera (Apolodoro, p. 82-83).

En toda esta historia sobre su vida lo interesante es ver cómo fue evolucionando como hechicera. Como la Circe que se encontraba enamorada de Odiseo, la vida y la magia de Medea están vinculadas a la vida de otro héroe a modo de auxiliar que facilita la victoria de su amado, pero que, por los numerosos problemas y la final traición de este último, termina por convertirse en un personaje antagónico. Si antes podía considerarse una heroína, ahora posee una gran cantidad de rasgos terroríficos y malignos, ya que poco a poco, con sus actos, ha ido perdiendo su humanidad (Caro Baroja, 1993, p. 47). Medea tendía hacia la necromancia, y en sus invocaciones se dirige hacia numerosos monstruos y animales oscuros, además de servir culto a divinidades oscuras como Hécate, diosa de la brujería. Si tenemos que darle un calificativo correcto a Medea sería el de bruja trágica, 
vengativa y atormentada debido al desamor (Caro Baroja, pp. 50-53). Cuando queremos ver cómo se representa a Medea, la encontramos en la mayoría de las ocasiones acompañada de Jasón, de sus hijos vivos o huyendo después de asesinarlos [2]. En muchas imágenes la podemos vislumbrar realizando sus pociones y brebajes mágicos, además de algún tipo de alusión o atributo que la vincula con los viajes que realizó con los Argonautas.

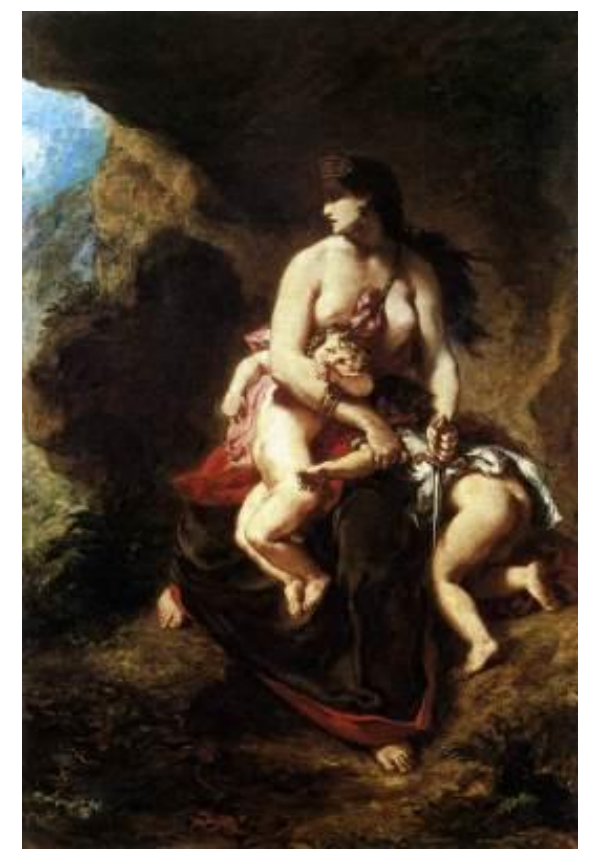

2. Delacroix, E. (1938), Medea a punto de matar a sus hijos. Museo del Louvre: Paris

\section{Las señoras de Tesalia}

Tesalia fue conocida por ser una rica tierra, que albergó a algunas de las más poderosas hechiceras de este tiempo, y donde se desarrolló un importante culto a Hécate. Autores como Lucano, en su Farsalia (Lucano, 1992, p. 374), han perfilado el poder de las hechiceras de Tesalia como maligno e inexplicable, con un lenguaje enigmático y misterioso. Eran practicantes de la magia erótica o amatoria más que cualquier otra diosa, bruja o hechicera que hemos referido hasta ahora. Las brujas son personas con fuertes personalidades y en un mundo en el que prima el deseo y las pasiones, es indispensable poseer una. Pero se supone que la hechicera antigua tiene una cierta hipertrofia en cuanto a ciertos rasgos de su carácter. En relación con la magia amatoria de la que hablábamos y las hechiceras que la practican, a nivel histórico se las ha asociado con este tipo de práctica por la creencia patriarcal de que la mujer, en especial las de este tipo, no son 
capaces de mantenerse fieles y que harán lo que esté en su mano para conseguir sus propósitos amatorios, siendo incluso capaces de transformarse en seres monstruosos para ello o haciendo uso de la nigromancia (Aranda, 2016, pp. 142-143).

Una de las obras clásicas donde más relevancia toma la zona de Tesalia es $L a$ Metamorfosis o el Asno de Oro de Apuleyo (Apuleyo, 1989, p. 62), y es aquí donde podemos encontrar a una de estas brujas, Pánfila. En una de las narraciones de esta Metamorfosis, el protagonista Lucio llega a Hípata, Tesalia, país de encantamientos, quedándose en la casa de Milón, marido de Pánfila, hechicera y nigromante. Ella efectúa sus hechizos por la noche, cuando consigue preparar sus filtros de amor en su cámara de brujería, poseyendo una gran cantidad de instrumentos e ingredientes para sus conjuros y ensalmos. Pánfila realizaba conjuros de magia asociativa, donde para atraer al joven que más deseaba debía usar un pelo o ropa de este, además de conjurar una serie de transformaciones convirtiéndose en un ser conocido como Striges o bruja vampiro (García, p. 47).

En el Asno de Oro las brujas tienen un papel importante en el desarrollo de la obra, por lo que podemos ver que Pánfila no sería la única en aparecer. Se conoce que, incluso antes de conocer a Pánfila, en el camino, uno de los compañeros de Lucio fue atacado por dos brujas por haber rechazado los favores sexuales de una de ellas; está hablando de Pantia y su hermana Meroe.

Tesalia se considera una región condenada, donde las brujas que la habitan invocaban a los muertos y dominaban todos los elementos que componen el mundo, y Ericto (Erictho) es la bruja más siniestra de la región. Mujer abominable, con cabellos enmarañados y una cara pútrida y consumida, que se enorgullece de ser una persona marginada. Para ella es preferible convocar a divinidades oscuras y malignas. Ladrona de cadáveres que usa para alimentarse y para sus conjuros, utiliza métodos que el resto de los magos ignoran. Las serpientes que anidaban en su pelo eran su principal atributo, además de otros animales salvajes como perros, búhos o lobos [3]. Vivía una vida salvaje, practicando rituales que estaban completamente prohibidos, como la búsqueda de sangre, por cualquier medio, para su consumo o para su magia. Era, en definitiva, una mujer peligrosa, que podía arremeter contra la integridad de cualquier persona y realiza todo tipo de abominaciones nigrománticas (Aranda, pp. 145). 


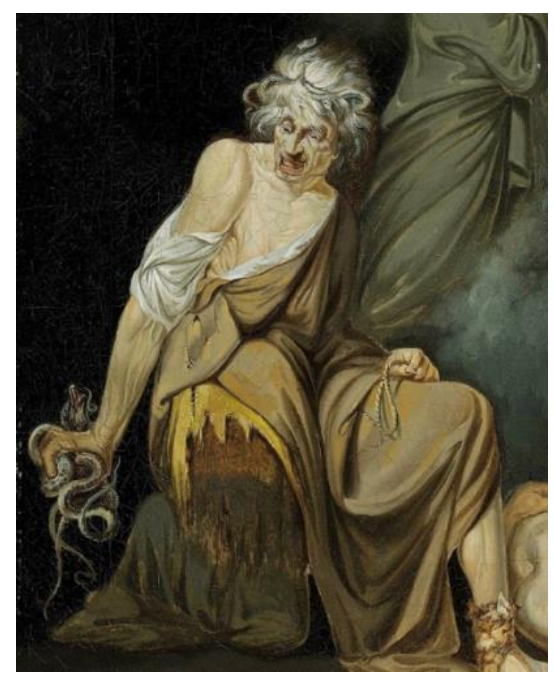

3. Hamilton, J. (1776), Sexto Pompeyo consulta a Erictho

\section{Las brujas venales}

Dentro de la magia amatoria, existe una derivación en la que nuestras hechiceras tienen que tomar partido en las relaciones amorosas de otras personas. Encarnan el papel de celestinas que, mediante el uso de sus brebajes y palabras, pervierten a los jóvenes, aunque también pueden realizar sus prácticas en su propio beneficio sexual, como es el caso de Canidia [4]. Esta hechicera y prostituta, junto con su compañera Sagana, quiere que su antiguo amante, Varo, vuelva a su lecho. Primero lo intenta con encantamientos y drogas, pero, viendo que esto no tiene resultado, pasa a tramar un plan nacido de las artes oscuras y la magia negra. Toma, poseída por su deseo sexual, la médula y el hígado de un niño o adolescente, dejándolo morir para realizar una fuerte pócima de amor, ayudada por una compañía de igual calaña que ella (García, p. 48). Tanto Canidia como Sagana se presentan como mujeres similares a Ericto, con rostros pálidos, de avanzada edad, muy escandalosas, y que siguen rodeadas de seres y criaturas salvajes.

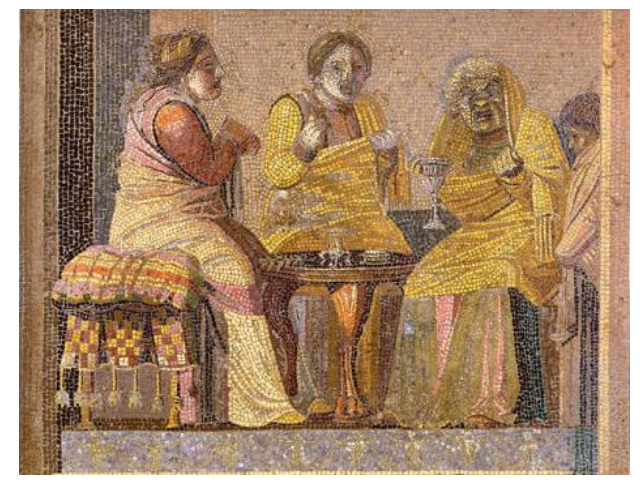

4. Anónimo (s. f.), Mosaico Canidia. Museo Arqueológico Nacional: Pompeya 
Realmente son personajes sin ningún rastro de bondad, solo piensan en su propio beneficio físico y personal, sin que les perturbe el tener que matar a un niño para conseguir sus cometidos. Las brujas de esta zona (ellas también pertenecen a la zona de Tesalia) son poderosas, peligrosas y poseen una verdadera astucia que combinan al reunirse en aquelarres donde apoyarse y ayudarse las unas a las otras (Aranda, pp. 145-147).

Por último, dentro de este pequeño grupo de venales, debemos mencionar a Dipsas, conocida como la alcahueta o meretriz según Ovidio en sus Amores (Ovidio, 2006, p. 6), en este caso ella representa la figura de la bruja vieja y aficionada a la bebida. Al igual que el resto de las brujas que conocemos poseía enormes conocimientos de botánica y el poder de metamorfosearse en ave nocturna, además de poder mantener contacto con los muertos. Pero, como ya hemos dicho, no solo poseía los poderes comunes a toda bruja de su tiempo, sino que Dipsas era una reconocida alcahueta que, con el don de la palabra zalamera, atraía a jóvenes que intentaba prostituir, siguiendo la línea de los que hacían Canidia y Sagana, aunque no con una maldad tan arraigada como ellas (Caro Baroja, pp. 55-56).

\section{Conclusión}

Durante todo el articulo hemos podido clarificar que la existencia de las brujas y hechiceras no es original de la época de la Inquisición o de la caza de brujas en el siglo XVII. Estas mujeres siempre han formado parte de la sociedad desde tiempos muy antiguos y nos ha quedado constancia de ello en las diferentes fuentes y obras artísticas que hemos podido encontrar. Se ha esclarecido que, pese a que sus autores las representen de formas diferente y con historias completamente opuestas, existen numerosos elementos habituales dentro de su programa iconográfico, además de la visión común que se ha tenido de ellas dentro del mundo del arte y literario, estableciéndose así un arquetipo de bruja/hechicera que aún perdura en la actualidad.

\section{Recursos Bibliográficos}

Apolodoro. (1985), Biblioteca mitológica. Editorial Gredos: Madrid.

Apuleyo, Lucio. (1989), La Metamorfosis o el Asno de Oro. Editorial Alianza: Madrid 
Aranda, J. A. (2016), Diosas y hechiceras: La visión de la magia y la mujer en la antigüedad greco-romana. Raudem: Revista de estudios de las mujeres, n. ${ }^{\circ} 4$.

Caro Baroja, Julio. (1993), Las brujas y su mundo. Alianza: Madrid

Dijkstra, Bram. (1986), Ídolos de perversidad. La imagen de la mujer en la cultura de fin de siglo. Editorial Debate: Barcelona.

Eurípides. (1977), Tragedias. Editorial Gredos: Madrid.

Elvira Barba, Miguel Ángel. (2008), Arte y Mito, Manual de Iconografía clásica. Sílex Ediciones S. L: Madrid.

García, M. (2005), 'De maga a bruja. Evolución de la hechicera en la Antigüedad clásica'. En Pedregal, María Amparo. y González, Marta (eds.). Venus sin espejo. Imágenes de mujeres en la Antigüedad clásica y el cristianismo primitivo. KRK Ediciones, Oviedo.

Homero. (1974), Odisea. EDAF, Editoriales-Distribuciones, S. A: Madrid.

Levi, Eliphas. (1988), Historia de la Magia. Editorial Kier: Buenos Aires.

Lucano, Marco. (1992), La Farsalia. Consejo Superior de Investigaciones Científicas: Madrid.

Luck, Georg. (1995), Arcana Mundi. Magia y Ciencias Ocultas en el mundo griego y romano. Editorial Gredos: Madrid.

Rodas, Apolonio. (1996), Argonautica. Editorial Gredos: Madrid.

Wulff Alonso, Fernando. (1997), Fortaleza asediada, diosas, héroes y mujeres poderosas en el mito griego. Ediciones Universidad de Salamanca: Salamanca. 